\title{
Time of Day is Associated with Opioid Prescribing for Low Back Pain in Primary Care
}

\author{
Lindsey M. Philpot, $\mathrm{PhD}, \mathrm{MPH}{ }^{7}$, Bushra A. Khokhar, $\mathrm{MS}^{7}$, Daniel L. Roellinger, $\mathrm{BS}^{7}$, Priya Ramar, $\mathrm{MPH}^{7}$, \\ and Jon O. Ebbert, MD, MSc ${ }^{1,2}$
}

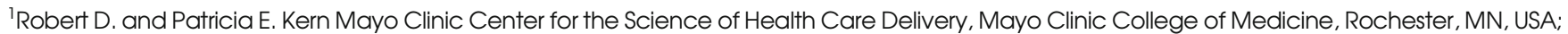
${ }^{2}$ Primary Care Internal Medicine, Mayo Clinic College of Medicine, Rochester, MN, USA.

KEY WORDS: back pain; pain; ambulatory care; physician behavior.

J Gen Intern Med 33(11):1828-30

DOI: $10.1007 / \mathrm{s} 11606-018-4521-8$

(C) Society of General Internal Medicine 2018

\section{INTRODUCTION}

An estimated 29\% of US adults have an episode of low back pain (LBP) over a 3-month period.' Opioids may be effective for short-term LBP pain relief, but evidence for long-term efficacy is limited.

The timing of healthcare provision may influence process measures and clinical outcomes. In primary care, an increased likelihood of antibiotic prescribing for acute respiratory infection has been observed with appointments later in a clinic session. ${ }^{2}$ No previous studies have evaluated the impact of appointment time of day on the provision of opioids to patients with LBP.

\section{METHODS}

We used administrative billing data, prescription data, and outpatient appointment scheduling data identifying all patients with a primary care provider appointment for LBP between January 1, 2015, and December 31, 2015, at Mayo Clinic in Rochester, Minnesota. Patient visits were sampled from administrative billing data using International Classification of Diseases, 9th Revision (ICD-9) and 10th Revision (ICD-10) diagnosis codes for LBP. Patients were excluded if they had a diagnosis code of spinal fracture, pregnancy, vehicular accidents, neoplasms, osteomyelitis, and lumbar surgery in the preceding 30 days of LBP diagnosis, or if they were enrolled on a controlled substance agreement (CSA) for chronic opioid therapy. Institutional guidelines recommend enrolling patients in a CSA if they are expected to be on a DEA Schedule II, III, or IV medication for $\geq 3$ months. Enrollment is not expected for hospice, nursing home, palliative care, or group home patients. The Mayo IRB reviewed and approved this research.

Published online July 2, 2018
Patient-level factors evaluated included age, gender, race, marital status, education, employment status, alcohol risk, current tobacco use, average reported pain level, scheduled appointment duration as a proxy of appointment complexity, and age-weighted Charlson Comorbidity Index (CCI). Pain level was calculated as the average of documented pain levels during 2015. We employed a 3-year window prior to appointment and calculated age-weighted CCI. The CCI was dichotomized to $>3$ or $\leq 3$.

Provider factors evaluated included provider type (physician, advanced practice provider, medical resident/fellow), years in clinical practice, patient complexity weighted panel size, and average billed visits per day as a proxy for clinic time. Primary exposure was scheduled appointment time for LBP. Primary outcome was an opioid prescription for buprenorphine, codeine, fentanyl, hydromorphone, hydrocodone, methadone, morphine, oxycodone, oxymorphone, or tramadol identified within our electronic prescribing record.

\section{STATISTICAL ANALYSIS}

Unadjusted and adjusted logistic regression models assessed scheduled appointment time against an opioid prescription during a LBP appointment. Multivariable models adjusted for patient and provider-level factors including provider as a random effect. Patient and provider-level factors were included within multivariable models when univariate modeling against the primary outcome (receipt of an opioid prescription) were $P<0.05$. We present unadjusted and adjusted point estimates (odds ratios, OR) with the associated 95\% confidence interval $(95 \% \mathrm{CI})$ along with model $P$ values, and the intraclass correlation coefficient (ICC) to represent the amount of similarity observed in prescribing by each provider within the mixed effect models.

\section{RESULTS}

Over the study period, we identified 2772 patient visits for LBP, $19.8 \%$ of which received an opioid prescription (Table 1). Appointments for LBP occurring later in the day had significantly higher odds of resulting in an opioid 
Table 1 Patient Characteristics by Receipt of an Opioid Prescription, Patient Visit $(n=2772)$

\begin{tabular}{|c|c|c|c|c|}
\hline & \multirow{2}{*}{$\frac{\text { Overall sample }}{n=2772(100 \%)}$} & \multirow{2}{*}{$\begin{array}{l}\text { Opioids prescribed } \\
n=549(19.8 \%)\end{array}$} & \multirow{2}{*}{$\frac{\text { Opioids not prescribed }}{n=2223(80.2 \%)}$} & \multirow[t]{2}{*}{$P$ value } \\
\hline & & & & \\
\hline Patient age, median (IQR) & $51.1(36.4-62.9)$ & $49.9(37.8-60.3)$ & $51.2(36.0-63.3)$ & 0.893 \\
\hline \multicolumn{4}{|l|}{ Patient sex, $N(\%)$} & 0.433 \\
\hline Female & $1556(56.1)$ & $300(54.6)$ & $1256(56.5)$ & \\
\hline \multicolumn{4}{|l|}{ Race, $N(\%)$} & 0.071 \\
\hline Black & $116(4.2)$ & $14(2.6)$ & $102(4.6)$ & \\
\hline White & $486(89.7)$ & $508(92.5)$ & $1978(89.0)$ & \\
\hline Others & $151(5.4)$ & $25(4.6)$ & $126(5.7)$ & \\
\hline Unknown & $19(0.7)$ & $2(0.3)$ & $17(0.7)$ & \\
\hline \multicolumn{4}{|l|}{ Marital status, $N(\%)$} & 0.188 \\
\hline Divorced & $261(9.4)$ & $57(10.4)$ & $204(9.2)$ & \\
\hline Married & $1814(65.4)$ & $369(67.2)$ & $1445(65.0)$ & \\
\hline Single & $518(18.7)$ & $85(15.5)$ & $433(19.5)$ & \\
\hline Widowed & $175(6.3)$ & $38(6.9)$ & $137(6.2)$ & \\
\hline Unknown & $4(0.1)$ & $0(0.00)$ & $4(0.1)$ & \\
\hline \multicolumn{4}{|c|}{ What is the highest grade or level of school that you have completed? $N(\%)^{*}$} & $<0.001$ \\
\hline High school or less & $654(23.6)$ & $122(22.2)$ & $532(23.9)$ & \\
\hline Some college or 2-year degree & $944(34.0)$ & $232(42.3)$ & $712(32.0)$ & \\
\hline 4-year college graduate & $457(16.5)$ & $75(13.7)$ & $382(17.2)$ & \\
\hline Post-graduate studies & $284(10.2)$ & $45(8.2)$ & $239(10.8)$ & \\
\hline Unknown & $433(15.7)$ & $75(13.6)$ & $358(16.1)$ & \\
\hline \multicolumn{4}{|c|}{ What is your current employment status (check all that apply)? $N(\%)^{*}$} & 0.002 \\
\hline Employed & $1290(46.5)$ & $260(47.4)$ & $1030(46.3)$ & \\
\hline Full-time homemaker & $72(2.6)$ & $13(2.4)$ & $59(2.6)$ & \\
\hline Retired & $595(21.5)$ & $112(20.4)$ & $483(21.7)$ & \\
\hline Self-employed & $143(5.2)$ & $40(7.3)$ & $103(4.6)$ & \\
\hline Unemployed & $120(4.3)$ & $23(4.2)$ & $97(4.4)$ & \\
\hline Work disabled & $72(2.6)$ & $25(4.6)$ & $47(2.1)$ & \\
\hline Other & $109(3.9)$ & $14(2.6)$ & $95(4.3)$ & \\
\hline Unknown & $371(13.4)$ & $62(11.1)$ & $309(14.0)$ & \\
\hline \multicolumn{4}{|c|}{ Felt the need to cut down on alcohol consumption, $N(\%)^{*}$} & 0.062 \\
\hline No & $2193(79.1)$ & $447(81.4)$ & $1746(78.5)$ & \\
\hline Yes & $141(5.1)$ & $38(6.9)$ & $103(4.6)$ & \\
\hline Unknown & $438(15.8)$ & $64(11.7)$ & $374(16.9)$ & \\
\hline \multicolumn{4}{|l|}{ Current tobacco use, $N(\%)^{*}$} & $<0.001$ \\
\hline Never & $1165(42.0)$ & $199(36.2)$ & $966(43.4)$ & \\
\hline Ever & $1228(44.3)$ & $290(52.8)$ & $938(42.2)$ & \\
\hline Unknown & $379(13.7)$ & $60(11.0)$ & $319(14.4)$ & \\
\hline \multicolumn{4}{|c|}{ Charlson Comorbidity Index (CCI), $N(\%)$} & 0.546 \\
\hline 3 or less & $2362(85.2)$ & $468(85.2)$ & $1894(85.2)$ & \\
\hline Greater than 3 & $410(14.8)$ & $81(14.8)$ & $329(14.8)$ & \\
\hline \multicolumn{5}{|l|}{ Average pain score, $N(\%)^{\dagger}$} \\
\hline No/mild average pain $(0-2.9)$ & $1072(38.7)$ & $112(20.4)$ & $960(43.2)$ & $<0.001$ \\
\hline Moderate average pain $(3.0-6.9)$ & $1390(50.1)$ & $341(62.1)$ & $1049(47.2)$ & \\
\hline Severe average pain $(\geq 7.0)$ & $288(10.4)$ & $96(17.5)$ & $192(8.6)$ & \\
\hline Unknown & $22(0.8)$ & $0(0.0)$ & $22(1.0)$ & \\
\hline
\end{tabular}

*Pearson's chi-square test $p<0.05$

${ }^{\dagger}$ Mann-Whitney non-parametric test $p<0.05$

Table 2 Unadjusted and Adjusted Mixed Effect Logistic Regression Measuring Impact of Appointment Time on Receipt of Opioid Prescription for Patients with Low Back Pain

\begin{tabular}{|c|c|c|c|c|c|c|c|c|}
\hline & \multirow[t]{2}{*}{$n(\%)$} & \multicolumn{3}{|c|}{ Unadjusted model } & \multicolumn{4}{|c|}{ Adjusted model } \\
\hline & & OR & $95 \% \mathrm{CI}$ & $P$ value & OR & $95 \% \mathrm{CI}$ & $P$ value & $\operatorname{ICC}(\%)$ \\
\hline \multicolumn{9}{|l|}{ Morning versus afternoon } \\
\hline 8:00 a.m. $-11: 59$ p.m. & $1259(46.8)$ & Ref & - & - & Ref & - & - & - \\
\hline 12:00 p.m. $-4: 59$ p.m. & $1433(53.2)$ & 1.25 & $1.03-1.52$ & 0.022 & 1.14 & $0.89-1.45$ & 0.306 & 9.26 \\
\hline \multicolumn{9}{|l|}{ 3-hour time blocks } \\
\hline 8:00 a.m. $-10: 59$ a.m. & $1001(37.2)$ & Ref & _ & - & Ref & - & - & \\
\hline 11:00 a.m.-1:59 p.m. & $636(23.6)$ & 1.24 & $0.955-1.60$ & 0.107 & 1.31 & $0.95-1.81$ & 0.103 & 9.54 \\
\hline 2:00 p.m. $-4: 59$ p.m. & $1055(39.2)$ & 1.48 & $1.19-1.84$ & 0.001 & 1.41 & $1.06-1.87$ & 0.017 & 9.54 \\
\hline \multicolumn{9}{|l|}{ Session time blocks } \\
\hline First hour (8:00-8:59 a.m., 1:00-1:59 p.m.) & $659(24.5)$ & Ref & - & - & Ref & - & - & - \\
\hline Second hour (9:00-9:59 a.m., 2:00-2:59 p.m.) & $703(26.1)$ & 1.22 & $0.92-1.61$ & 0.173 & 1.24 & $0.86-1.78$ & 0.245 & 8.58 \\
\hline Third hour (10:00-10:59 a.m., 3:00-3:59 p.m.) & $852(31.6)$ & 1.34 & $1.03-1.75$ & 0.031 & 1.15 & $0.81-1.62$ & 0.441 & 5.65 \\
\hline Fourth hour (11:00-11:59 a.m., 4:00-4:59 p.m.) & $478(17.8)$ & 1.46 & $1.08-1.97$ & 0.014 & 1.60 & $1.09-2.36$ & 0.016 & 1.47 \\
\hline
\end{tabular}

Adjustment factors: education, employment, tobacco use, average pain score, provider years in practice, scheduled appointment length, random provider effect

OR, odds ratio; CI, confident interval; ICC, intraclass correlation coefficient of the random provider effect 
prescription in two of our three controlled modeling approaches (Table 2).

\section{DISCUSSION}

Our findings parallel the literature observing the same phenomenon with antibiotics. ${ }^{2}$ Adults visiting a primary care setting for acute respiratory tract infections had been previously observed to be more likely to receive a prescription for an antibiotic the later they were seen during 4-h clinic sessions ( 8 a.m. to noon and 1 to 5 p.m.). Relative to the first hour of a clinic session, the likelihood of antibiotic prescribing was significantly higher in the third and fourth hours. Our adjusted model demonstrated significantly higher odds of receiving an opioid in the fourth hour compared to the first. Linder et al. ${ }^{2}$ proposed that this may be due to decision fatigue. Workplace fatigue has been observed to be associated with deviations from professional guidelines, and practice volume has been observed to be associated with decision-making style. As medical care becomes increasingly complex, interventions designed to reduce decision fatigue and support decisionmaking may serve to improve patient care and safety with opioid medications.

Corresponding Author: Jon O. Ebbert, MD, MSc; Primary Care Internal Medicine Mayo Clinic College of Medicine, Rochester, MN, USA (e-mail: ebbert.jon@mayo.edu).

Funding Information This study was funded by the Robert D. and Patricia E. Kern Center for the Science of Healthcare Delivery and the Mayo Clinic College of Medicine.

\section{Compliance with Ethical Standards:}

The Mayo IRB reviewed and approved this research.

Conflict of Interest: LMP reports funding from GSK for research not related to the current work. No other authors have conflicts of interest to report.

\section{REFERENCES}

1. Centers for Disease Control and Prevention. Health, United States, 2014 Individual Charts and Tables: Spreadsheet, PDF, and PowerPoint Files. 2015; https://www.cdc.gov/nchs/hus/contents2014.htm\#046. Accessed 1 May 2018.

2. Linder JA, Doctor JN, Friedberg Mw, et al. Time of day and the decision to prescribe antibiotics. JAMA Intern Med 2014;174(12):2029-2031.

3. Kardouni JR, Shing TL, Rhon DI. Risk factors for low back pain and spine surgery: a retrospective cohort study in soldiers: Am J Prev Med 2016;51(5):e129-e138.

4. Romanelli RJ, Shah SN, Ikeda $\mathbf{L}$, et al. Patient characteristics and healthcare utilization of a chronic pain population within an integrated healthcare system. Am J Manag Care 2017;23(2):e50-e56.

5. Dai H, Milkman KL, Hofmann DA, Staats BR. The impact of time at work and time off from work on rule compliance: the case of hand hygiene in health care. J Appl Psychol 2015;100(3):846-862.

6. Kaplan SH, Greenfield S, Gandek B, Rogers WH, Ware JE Jr. Characteristics of physicians with participatory decision-making styles. Ann Intern Med 1996;124(5):497-504. 